\title{
Second Interfacial Polymerization of Thin-film Composite Hollow Fibers with Amine-CDs for Pervaporation Dehydration
}

\author{
Xi Yu${ }^{1}$, Tengyang Zhu ${ }^{1}$, Sheng $\mathrm{Xu}^{1}$, Xuan Zhang ${ }^{1}$, Ming $\mathrm{Yi}^{1}$, Shu Xiong ${ }^{2}$, Shutong Liu ${ }^{1}$, \\ Liang Shen ${ }^{1}$, and Yan Wang ${ }^{1}$ \\ ${ }^{1}$ Huazhong University of Science and Technology \\ ${ }^{2}$ Huazhong University of Science and Technology - Wuchang Campus
}

August 28, 2020

\begin{abstract}
High performance thin-film composite (TFC) hollow fiber membranes have been developed for pervaporation dehydration by second interfacial polymerization (SIP) modification with 3 kinds of amine-functionalized $\beta$-cyclodextrin (amine-CDs), which were synthesized by modifying $\beta$-CD with ammonia, ethylenediamine (EDA) and tris(2-aminoethyl)amine, respectively. The chemical properties of amine-CDs and SIP-modified TFC membranes were characterized by various techniques. The effects of amine-CD type and SIP parameters ( $\mathrm{pH}$ or concentration of CD-EDA solution) were studied systematically to acquire the optimized selective layer of TFC membranes for ethanol dehydration. Among all SIP-modified TFC membranes, the one with SIP by $2 \mathrm{wt} \%$ CD-EDA aqueous solution $(\mathrm{pH}=2)$ exhibited the most outstanding separation performance with a ultra-high permeation flux $(3018.0 \pm 12.0 \mathrm{~g} / \mathrm{m} 2 . \mathrm{h})$ and permeate concentration $\left(98.7 \pm 0.2 \mathrm{wt} \%\right.$ water) at $50{ }^{\circ} \mathrm{C}$ (equivalent to separation factor of 415), contributed by the effectively incorporated $\mathrm{CD}$ with rich hydrophilic functional groups and intrinsic nanocavities facilitating the passage of water molecules.
\end{abstract}

\section{Hosted file}

yuxi-Manuscript-20200809.docx available at https://authorea.com/users/354684/articles/ 478171-second-interfacial-polymerization-of-thin-film-composite-hollow-fibers-withamine-cds-for-pervaporation-dehydration 